\title{
HAROLDO DE CAMPOS E A INTERPRETAÇÃO LUCIFERINA
}

\author{
Andrea Lombardi* \\ Universidade Federal do Rio de Janeiro
}

\begin{abstract}
Resumo:O caminho que Haroldo de Campos empreende em sua leitura de Dante Alighieri (Traduzir e Trovare Pedra e luz na poesia de Dante) abre para uma leitura audaz da obra do fundador da língua e tradição cultural italiana. Traduzindo partes do Paradiso, ele invoca a metáfora da luz, que remete à visão de um grande intelectual medieval da época de Dante: Robert Grosseteste. Traduzir, para Haroldo, equivale a ler de forma hipercrítica, provocando uma desestabilização radical no texto. Tresler, tresluzir, transcriar, transparecer: são conceitos produto do agrupamento entre leitura/criação, luz e o prefixo trans ou três. Tresler, por ex., pode ter o significado de ler às avessas, mas também: "perder o juízo"ou "dizer tolices". Há, portanto, um movimento vorticoso em diagonal ou "às avessas" típico de Haroldo de Campos, que salienta uma tensão entreo intelecto em Dante e o caminho místico, que a luz paradisíaca deixa transparecer. O que leva Haroldo a uma recuperação de Lúcifer (Satanás), de acordo com a etimologia "o que traz luz", que segundo uma tradição popular, é dono da sabedoria superior, negada ao homem comum. Uma singular analogia com o Golem, da tradição hebraica.
\end{abstract}

Palavras-chave: Haroldo de Campos. Dante Alighieri. Teoria da tradução. Divina Comédia.Transcriação.

\footnotetext{
* Formação em Letras, Universitàdegli Studi de Roma, "La Sapienza". Formação em Teoria Musical e Clarinete, Conservatoriodi Musica "S Pietro a Maiella" de Nápoles. Doutorado em Letras (Teoria Literária e Literatura Comparada) pela Universidade de São Paulo. Professor adjunto da Universidade Federal do Rio de Janeiro, Faculdade de Letras, Departamento de Letras Neolatinas. Rio de Janeiro, Rio de Janeiro, Brasil. E-mail: lombardi.andrea@gmail.com
} 


\title{
HAROLDO DE CAMPOS AND THE LUCIFEROUS INTERPRETATION
}

\begin{abstract}
The path that Haroldo de Campos takes on his reading of Dante Alighieri (Pedra e Luz na Poesia de Dante) opens a new view on the work of the great Italian author. Translating parts of the Paradiso, he invokes the metaphor of light, which alludes to Robert Grosseteste vision, a great intellectual of the Middle Ages, of Dante's age. Translating, to Haroldo de Campos, is equivalent to realize a hypercritical reading, which causes a radical destabilization in the text. Tresler, tresluzir, transcriar, transparecer: these all are concepts Haroldo uses. They are the product of the coupling between reading/creating, light and the prefix trans or tres. Tresler, e.g., whose meaning may be "read in reverse", can also be read as "losing his mind" or "talking nonsense". There is therefore a vortical motion in diagonal or "upside down" typical of Haroldo de Campos, which highlights a tension between intellect and mystical path in Dante, revealed by the Paradise light. And this makes Harold recover Lucifer (Satan), from his etymology "which brings light", and who, according to popular tradition, is the owner of superior wisdom, denied to the common man. A striking analogy with the Golem, of the Jewish tradition.
\end{abstract}

Keywords: Haroldo de Campos. Dante Alighieri. Translation theory. Divine Comedy. Transcreation.

A primeira forma corporal, que alguns chamam Corporeidade (corporeitatem), eu mantenho ser a luz. [...] Corporeidade é o que necessariamente segue da extensão da matéria em três dimensões.

Robert Grosseteste

Em sua leitura de Dante Alighieri, empreendida em vários momentos de sua obra e publicada em Pedra e luz na poesia de Dante, Haroldo de Campos (1998) trilha um caminho muito ousado, na leitura e na tradução: algo denovo em relação às interpretaçõesjá realizadas na extensa fortuna crítica de Dante. Dante é o marco da tradição literária e cultural italiana e europeia por excelência. O próprio Dante foi objeto de execração: ele quis colocar, entre 
outras o Papa Celestino V no Inferno e teve suaobra posta noindexdos livros da Inquisição: por suas posições heréticas epor sua língua carregada de realismo cotidiano. Tratar de Dante é um desafio, pois há múltiplas gerações de leitores, tradutores, retradutores: Haroldo sugere, por exemplo, ler Guido Cavalcanti, grande mestre de Dante e do stil novo e amigo do poeta, através da singular leitura que o próprio Dante fez do texto de Cavalcanti, proposto na tradução inglesa por Ezra Pound e traduzido, do inglês para o português.O conceito do Amor-central para o nascimento da poesia moderna e para Dante - transforma-se em luz:

Nel ciel che più della sua luce prende, fù ioe vidi cosa che ridire ne sa ne può chi di lassù discende (Par. I, 4-6)

[No alto céu, onde mais a luz se incende Eu fui, e vi tais coisas, que dizer

Não sabe ou pode quem de lá descende] (CAMPOS, 1998,p. 85)

A luz divina, metáfora de uma luz ofegante, absoluta, definitiva é intraduzível. Ela apresenta um desafio à representação, pois "não se pode" ou "não se sabe" repetir o que se viu. A viagem, que iniciara no signo do Amor por Beatriz, muda de rumo, pois se fixa num conjunto de luzes resplandecentes.

Seguindo Erich Auerbach (1991), o grande crítico "clássico", Haroldo aponta a tendência de Dante em abarcar o sistema de Aristóteles com os vigorosos exemplos de neoplatonismo e de misticismo:

No Paraíso, empenhado em reconciliar o sistema tomista com a ideologia místico-amorosa do cor gentile (Auerbach), Dante prolonga, sustenta e totaliza essa especulação radiosa sobre um Amor que é Luz.(CAMPOS,1998, p. 70) 
O Amor, segundo Haroldo, em Dante torna-se luz ou, definitivamente, é luz. Dante evidentemente recupera uma visão herética, influenciado pelo neoplatonismo do amigo e mestre Guido Cavalcanti, e com isso assume também uma implícita defesa de seu suposto averroísmo, uma leitura de Aristóteles em contraste com a concepção cristã: "A mediação" - acrescenta Haroldo a propósito da tradução de Ezra Pound - se faz pelo trâmite da hipótese especulativa de que Guido Cavalcanti (1259-1300) tenha de algum modo conhecido a filosofia da luz de Robert Grosseteste (1168-1253), Bispo de Lincoln (Inglaterra), cujo pensamento sobre a luz reportamos na epígrafe. Grosseteste (numa tradução irônica: "A grande cabeça") foi considerado um dos homens mais eruditos de sua época. Colega de Roger Bacon, foi o primeiro chanceler da Universidade de Oxford que, portanto, contribuiu para fundar. Em numerosas publicações, Grosseteste deixou um decisivo legado para o caminho da ciência. Defendeu um movimento chamado significativamente perspectiva, algo que define uma concepção da ciência flexível e que, na Renascença, dará o nome a uma das mais revolucionárias transformações na visão. Pois a perspectiva acresce uma interpretaçãoà visãoe a transforma numa metáfora (ou seja: uma leitura, uma superposição em relação ao que é realmente visto). Entre os tratados redigidos por ele estão De sphera (sobre astronomia), De luce (sobre a metafísica da luz), em que defende que o mundo foi criado pela autodifusão em forma esférica de um ponto luminoso. Escreveu tambémDe iride (sobre o arco-íris) e comentários sobre a filosofia de Aristóteles. Mesmo não sendo considerada herética, a teorização da luz como elemento primordial, que Grosseteste faz com grande vigor, dá espaço a uma oposição, se não propriamente a um conflito, entre luz e energia divina: "La gloria di colui che tutto move/ per l'universo penetra, e risplende/ in una parte più e menoaltrove",[A glória de quem tudo o mais comove/ Pelo universo penetra e resplende,/ E mais, e menos, suas artes move] (CAMPOS, 1998, p. 85).O texto dá a entender que a glória divina penetra assim como a luz. E no Empíreu (o último ou o mais alto céu, o céu sobre o fogo), temos o lugar onde a luz se incandesce, ("nel ciel che più della sua luce prende": ou seja, um 
céu sobrecarregado de luz). Na famosa Epístola a Cangrande della Scala(mecenas de Dante em seu exílio de duas décadas de Florença), aparece uma expressão ainda mais explícita: Gloria Dei, sive luz, em tradução: glória de Deus, ou seja da luz, onde a glória é diretamente justaposta à luz:

Depois de ter antecipado tal verdade, ele continua falando do Paraíso por perífrases. E diz que foi naquele céu (o Empíreu) que recebeu de forma mais abundante a glória de Deus, ou seja da luz. ...É chamado de Empíreu, o que significa "céu ardente por seu próprio fogo". (ALIGHIERI, 2012, tradução minha)

Gloria Dei, sive lux, poder-se-ia dizer com Grosseteste. Aqui a essência de Deus tornou-se luz. A leitura que Dante faz da obra do amigo Guido Cavalcanti, portanto, parece estar incorporando as ideias de Grosseteste. A luz pode ser considerada uma ideia-base na Divina Comédia, mas é no Paraíso que ela se torna ideia fundamental. O Empíreo é reservado para anjos, deuses, santos e seres abençoados, um lugar que em cosmologias antigas deveria ser ocupado pelo fogo. De resto, a criatura à qual dedicamos o título desse texto, Lúcifer, aparece no Inferno, como criatura de luz, como esclarece Haroldode Campos:

Hibernado no gelo central, suspenso no vazio, reina Lucífer, o antigo "portador da luz" (lat., lucifer), também Lusbel, o mais belo dos anjos ("La creatura ch'ebbe il bel sembiante"), (Inf. XXXIV, 18), agora luz caída, ex-lume ("colui che fu nobil creato") e que caiu "folgoreggiando", Purg. XII, 25-25 (CAMPOS, 1998,p. 76)

O caminho da Comédia, do fogo do Inferno para as alturas árduas do Paraíso, passa por umatransformação, que é ao mes- 
mo tempo uma passagem do conceito de Amor ao deLuz e uma verdadeira conversão, pois provoca uma mudança existencial. É o texto que realiza, acompanha ou prefigura essa mudança, pois a viagem é ficcional, onírica. O caminho é, de certa forma, uma sublimação (do Amor, da morte da amada, de elementos terrenos) prefigurados pelos conceitos e pelas palavras. Uma máquina literária que descrevendo aparentemente o mundo, acabamoldando-o e recriando-o. Literatura para Dante (e para Haroldo de Campos) revela-se o engenho (necessariamente irônico) autorreflexivo, solilóquio profundo e conversa coral (com seus leitores).Algo poderoso, algo que se volta sobre a si mesmo: espelho reflexo de um olhar sobre a materialidade da escritura. Pode-se dizer que o caminho da literatura desvenda uma presença crescente, imponente de restos de sentido, nos interstícios do tecido da linguagem. A aventura da escrita é sempre mais aventura sobre a escrita, uma escrita que se ergue e vislumbra que a aventura está nela mesma e não é por ela "relatada". Remeto à abertura deum texto famoso do trans-tradutor brasileiro:

e começo aqui e meço aqui este começo e recomeço e remeço e arremesso/ e aqui me meço quando se vive sob a espécie da viagem o que importa não é a viagem mas o começo da por isso meço por isso começo escrever/ mil páginas escrever milumapáginas para acabar com a escritura para/ começar com a escritura para acabarcomeçar com a escritura por isso/ recomeço por isso arremeço por isso teço escrever sobre escrever é/ o futuro do escrever sobrescrevo sobrescravo em milumanoites miluma-/ páginas ou uma página em uma noite que é o mesmo noites e páginas/ mesmam ensimesmam onde o fim é o comêço onde escrever sobre o escrever/ é não escrever sobre não escrever[...].(CAMPOS, 1984, p. 1)

Uma escrita que em seus soluços, interrupções, vacilos tem a vocação de escutar-se/auscultar-se e faz da memória desse amál- 
gama sonoro motivo para ensimesmar-se. Essa é uma escrita (uma visão da escrita, uma interpretação criativa dessa escrita) que trata de num lado "fechado" da linguagem-escrita, seu lado místico ou anagógico (definido assim por Dante na Epístola a Cangrande della Scala). Ensimesmar-se, um típico verbo que Haroldo poderia ter retomado de Dante e que percebemos como perfeitamente contemporâneo. O começo/recomeço/remeço e ...arremesso e o meço (de medir) desestabilizam a ideia de um começo ontológico, definitivo.

Essa literatura nasce (na reflexão teórica) e renasce (nessa guinada haroldiana) fortalecida e recupera um ímpeto mágico do Romantismo (a começar pelo círculo "mágico" ou hermenêutico de Schleiermacher ou a vocação revolucionária de Novalis). Convém, nesse contexto, a propósito da influência da luz na obra de Dante e seu mestre Cavalcanti, lembrara crítica Maria Corti $(2003, p .9)$ que,em Scritti su Cavalcanti e Dante, afirma a ideia de uma imutabilidade do passado:

\begin{abstract}
Parafraseando os versos do trágico grego Agatão, que Aristóteles já lembrou em a Ética a Nicômaco (VI, I), Alberto Magno escreveu que Deus não consegue realizar uma única coisa: mudar o passado; quae enim facta sunt, fieri non possunt...(CORTI, 2003, p. 9)
\end{abstract}

Entretanto, na visão luciferina da literatura, que Haroldo de Campos constrói por meio de sua tradução de Dante, a literatura possui essa faculdade máxima, que nem a Deus pode ser atribuída: ela relê o passado, como sugere o narrador/escritor do famoso ensaio Kafka e seus precursores" (BORGES, 1989, p. 490-498).

e subverte esse passado que se revela fruto de uma construção literária (pense-se, como exemplo, no episódio bíblico do Salomão, em que o tempo é levado a se deter). É altamente provável que em sua tradução de Dante, Harol- 
do, seu engenhoso leitor, descubra uma coincidência sobre os imensos poderes da literatura. Pois é aliteratura, como Pierre Menard, como qualquer leitor em sua tarefa de releitura infinita, que relê o passado e nisso o transforma: o passado da história, de nossa história, da história literária. A literatura reorganiza o conjunto dos conhecimentos, das visões, das impressões. A leitura perpassa a tradução de Ezra Pound, pela própria retradução de Haroldo para o português: "agora Cavalcanti via Pound via Dante", glosa Haroldo: torna-se uma hiperleituraou hipertradução. Como o próprio texto afirma: Haroldo "traduz (treslê?/ tresluz)"(CAMPOS, 1998, p. 72).

O trabalho de tradução do Haroldo é uma tarefa árdua. E o adjetivo árduodefineseu estilo tradutório. Pois árduo, remonta ao latim arduus, ao celta sublime, ao galês mais alto e ao grego àrden $=$ no alto, Orth- os = reto, no alto, erigido (veja-se ortodoxo), da mesma raiz do persa $a r d a=$ alto, que parece remontar à raiz $a r=$ puxar, ..."levanto, para o alto" e parece descrever o movimento complexo e sublime da tradução (DEVOTO, 1990).

Aforaos seis cantos do Paraíso, a última das três partes deDivina Comédia, Pedra e luz na poesia de Dante, inclui a tradução das Rime Petrose, as mais ásperas e difíceis da produção poética de Dante e, finalmente, uma amostra de textos de Guido Guinizelli e de Dante, que podem ser considerados os textos básicos do Dolce Stil Novo, o movimento ao qual Dante se filia, ou melhor: o movimento que ele próprio define e cria como seu precursor. Ao coração gentil retorna Amor, de Guido Guinizelli, o manifesto poético deste que pode ser considerado o pai daquele movimento. O primeiro soneto de Dante (Ao coração gentil, de Amor cativo), da Vita Nuova, testemunha sua adesão ao Dolce Stil Novo; a resposta de Guido Cavalcanti por meio de outro soneto (Soneto 37) e uma famosa balada deste amigo de Dante completam o quadro. $\mathrm{O}$ volume termina com uma balada à moda toscana de autoria do próprio Haroldo de Campos, uma forma de conferir atualidade ao Duecento, dialogando com ele. 
As traduções, os ensaios e as notas desse grande poeta brasileiro proporcionam uma introdução ao texto original italiano que, mesmo para especialistas da língua, é bastante complexo, desmentindo em parte a crença de que a leitura do original sempre deve anteceder a leitura crítica. Os ensaios por si constituem um acréscimo significativo à fortuna crítica dantesca, vindo do outro lado do oceano, "por trás do sol", como Dante escreveu sobre o Canto de Ulisses (Inferno). O cerne dos resultados investigativos de Haroldo é uma problemática concentrada na forma de expressão, o que aponta para a dificuldade, umametafórica "impossibilidade" de expressão. Num universo feito de luzes resplandecentes, cintilações ofuscantes, espelhos (Paraíso, II, 97²) que forçam uma revisão das faculdades da imaginação (Paraíso, I, 88-903), o próprio intelecto se descobre incapaz de produzir signos adequados e a mente chega a seu limite: "a mente assim, diante do demasiado/ manjar, saiu de si, sobreexcedeu/ e já não sei lembrar quanto é passado" (Paraíso, XXIII, 43-45). Em italiano, aqui: "La mente mia cosi, tra quelle dape/ fatta più grande, di sé stessa scío / e che si fesse rimembrar non sape"(CAMPOS, 1998, p. 126-7). O intelecto transcende as leis e as condições de seu curso normal, sobreexcede(ou "sai de si", original italiano), o que equivale a uma espécie de morte e superação ou transcendência, uma experiência místico-anagógica.

No início do caminho tradutório de Haroldo parece estar a exortação de Ezra Pound, Make it new!, a partir do qual empreende uma releitura da poesia universal, por amostras, escolha. A viagem como metáfora da leitura constitui a introdução do II Canto do Paraíso e permite acompanhar uma profunda transformação na Comédia:

Ovoichesiete in piccioletta barca,/desiderosi d'ascoltar, seguiti/ dietro al mio legnoche cantando varca,// tornate a riveder li vostriliti:/ non vi mettete in pelago, chéforse,/ perdendo me, rimarrestesmarriti (Par. II, 1)

[Ó vós que em barca pequenina e lassa,/ Por amor de escutar, me haveis seguido/ A nau cantante que desonda e 
passa,...Volvei sem mais ao porto conhecido:/ O mar é alto, basta de porfía,Pois me perdendo, vos tereis perdido (CAMPOS, 1998, p. 98-99)

O barco com os leitores que chega ao porto é um modelo conhecido e a viagem, como transferência e transformação, domina a Comédia, pois ela é metáfora não somente da aventura do protagonista Dante, mas induz o leitor a uma outra viagem, que é, em seu propósito, transgressiva: contra o senso comum na leitura do texto conforme a época de Dante e, por outro lado, para superar as interpretações esquemáticas. A viagem permite uma ponte com uma viagem angustiada, relatada no Canto I do Inferno (22-27), onde o personagem Dante se encontra perdido, na selva escura.

E come quei che con lena affannata/ uscitofuordelpelago a lariva/ si volge a l'acqua perigliosa e guata,// cosil'animo mio, ch'ancor fuggiva,/ si volse a retro a rimirarlo passo/ che non lasciògiàmai persona viva (Inf. I, 22-27)

[E como quem a respirar arfava,/ Escapando do pélago à deriva, / E as águas perigosas remirava, ... assim minh'alma, ainda fugitiva,/ volveu a olhar atrás aquele passo/ Em que pessoa alguma ficou viva] (GRAÇA MOURA, 1996, p. 31)

O motivo da viagem terá, na Divina Comédia, seu emblema na aventura de Ulisses. Uma viagem que é comparada (pela angústia do perigo) a um voo, a um follevolo( "de'remifacemmo ali alfollevolo", "Já dão os remos asa ao voo tolo") (Inf., XXVI, 124, GRAÇA MOURA, 1996, p. 240-1). Um voo louco ou - como Haroldo propõe - tresloucado. Dante - como muitos autores apontaram - se identifica com Ulisses, pois sua própria viagem (a do Dante) é considerada uma loucura: "temo que a vinda mor loucura seja", declara Dante como personagem no Canto II, 35 (GRAÇA MOURA, 1996, p. 41). 
Há aqui uma identificação entre Dante e Ulisses. Dante-Ulisses afirma com seu exemplo uma leitura contra a tradição, uma leitura/ viagem/voo tresloucados, um adjetivo caro a Haroldo. A própria personagem de Ulisses, que na Divina Comédia adquire feições completamente diferentes do Ulisses do nóstos da Odisseia, é uma invenção de Dante, uma sua releitura. Pois esse Ulisses luciferino choca-se contra a suposta impossibilidade da representação e a necessidade de ir além, de ultrapassar as "colunas de Hércules", de enxergar o além, "o mundo sem gente." O Ulisses do Canto XXVI do Inferno representa uma releitura e uma distorção radical do herói da Odisseia, pois ultrapassa os limites do mundo conhecido, para além das míticas colunas de Hércules (ou seja de Gibraltar). Ele não é movido pela nostalgia, sua viagem não representa um nóstos, um retorno a Ítaca, nos braços de Penélope. O Ulisses de Dante é um navegador temerário e ousado, que empreende sua viagem, consciente de que será sua última. Ele sabe merecer ser punido pela ousadia, mas sacrifica sua vida em prol da virtude $e$ canoscenza, coragem e conhecimento. Não é necessariamente um suicida, mas, fugindo de certa forma do modelo da figura (que segundo Auerbach (1991) uniria exemplaridade e autenticidade histórica) ele é a sublimação pura do humano. O que move Ulisses é um plano, uma estratégia, um objetivo, em que ele - humano - irá resgatar covardia e rebaixamento: "Fatti non foste per viver come bruti,/ ma per seguir virtute e canoscenza"(Inf., XXVI, 119),[Feitos não fostes para viver como brutos,//Mas para seguir virtude e conhecimento] (GRAÇA MOURA, 1996, trad. adaptada).

O Ulisses de Dante grita em direção à tripulação temerosa, pois ele está em busca de algo que pertence ao futuro, procurando a montanha do Purgatório, que é também seu passado: sua origem, uma bandeira e um não lugar e, também, um caminho para redenção, para o resgate que coincide com sua morte. É o primeiro personagem que ousa e consegue descrever a própria morte. Ulisses, até o último instante convicto de sua ação radical, realiza a impossível descrição da própria morte, algo que é realizado, embora não possa teoricamente ser descrito, e que constitui o limite da 
literatura (e da vida), quando o mar se fecha sobre o navio e seus tripulantes. E Ulisses (de Dante) comenta: “e infinche'l mar fu sopra noirichiuso"(Inf., XXVI, 142), [e o mar finalmente sobre nós fechou] (GRAÇA MOURA, 1996, com adaptações) ${ }^{4}$.

A representação da superação extrema da morte e de sua representação - pois Ulisses é um protagonista testemunho de sua morte como um protagonista da literatura de testemunho, da literatura contemporânea- é resultado de uma tensão da linguagem, do texto poético de Dante, algo que inspira uma reflexão no plano teórico. A leitura pode experimentar uma sublimação, um voo para o alto, uma consciência de uma (im)possibilidade.

A cena da viagem descrita no Canto I do Paraíso leva para um percurso que atravessa diagonalmente o texto da Comédia, desde a revelação de Beatriz: uma visão que ofusca, que fita o sol e não recua.

Surge aos mortais por focos de fulgores/ Vários a luz do mundo; ...Essa luz repartindo-se fizera/ Noite aqui, dia lá, e agora branca/ Alumiava uma parte, e enegrecera// A outra; Beatriz vejo que estanca/ Do lado esquerdo, e os olhos no sol fita:/ Nem olho de águia que na luz esbranca (CAMPOS, 1998, p. 87-8)

Dante olha para Beatriz e olha o sol e ambos fixam estáticos a olhar a luz. A luz torna-se ofuscante. Há um momento de suspensão do texto, da compreensão. Pouco depois aparecem os enigmáticos versos: "Trasumanar significar per verba | non si poria" (Par.I, 70-1), ou seja: "Transumanar significar per verba/ não saberia" (CAMPOS, 1998,p. 91). Transumanar como transcriar é um ir além (como Ulisses), no terreno das palavras, pois o último canto do Paraíso, o XXXIII, alcança o ápice da inefabilidade:

Da quinci innanzi il mio veder fu maggio/ che 'l parlar mostra, ch'a tal vista cede, e cede la memoria a tanto oltraggio./ Qual è colüi che sognando vede, che dopo 'l sog- 
no/ la passione impressa rimane, e l'altro a la mente non riede (Par. XXXIII, 55-60)

[Desde esse instante o ver me foi demais, / calou-me a fala, que a tal vista expira,/ como expira a memória neste mais.// Que nem aquele que sonhando mira/ algo, e do sonho acorda e tem impressa/ a paixão, quando a mente o mais retira (CAMPOS, 1998, p. 152)

A partir desta explosão de luz no Paraíso a tradução de Haroldo oferece uma possibilidade de inversão radical, um efeito da operação de tradução, como caminho iluminador: "Cosmonauta em transnavegação luminosa. Como antes fora espeleólogo das profundezas terrestres em seu descenso ctônico, infernal, Dante, na culminação do Sacrato Poema, assiste à reconversão do cinético em figural, do óptico em icônico..." (CAMPOS, 1998,p. 74-5).

A culpa de Lúcifer, segundo leitura de Haroldo, foi de traspassar del segno, ultrapassar o limite, o signo, mas nisso Lúcifer encarna perigosamente a função do leitor, com ambas as características: sua ambição à luz, ao conhecimento, e sua necessária rebeldia à interpretação tradicional. A tradução sugere uma superação do texto original sendo uma "empresa luciferina". Ela aponta para uma "leitura retrocessiva do Inferno, agora como inverso simétrico da metáfora da luz", onde o Amor (visto como luz e fogo) é absolutamente ausente. Um verdadeiro paradoxo e uma leitura nova de Dante.

A luz que aparece com tanta força no Paraíso, uma "luz paradisíaca" - como foi chamada por Haroldo (1998, p. 67) em Pedra e luz e, ao mesmo tempo, "no Paraíso", empenhado em reconciliar o sistema tomista com a ideologia místico-amorosa do cor gentile(Auerbach), Dante prolonga, sustenta e totaliza essa especulação radiosa sobre um Amor que é Luz. Pedra e luz. Daqui uma ponte que passa pelas especulações de RobertGrosseteste, filósofo medieval e grande investigador da função da luz: 
A mediação se faz pelo trâmite da hipótese especulativa de que Guido Cavalcanti (c. 1259-1300) tenha de algum modo conhecido a filosofia da luz de Roberto Grosseteste (11681253), para quem: Lux prima forma in materia creata (...) Luz per se in omnem partem se ipsam diffundit. (CAMPOS, 1998, p. 71)

A propósito dessa ligação entre Cavalcanti e a metafísica da luz de Grosseteste, Maria Corti (2003, p. 118-120) acrescenta:

O aspecto talvez mais fascinante do Paraíso dantesco é a realização de uma grande poesia construída sobre dois momentos da atividade contemplativa: aquela do excessus mentis ou êxtase místico e outro da contemplação intelectual.

Dante (narrador) afirma aqui que

Nelcielchepiù de la sua luce prende/ fu' io, e vidi cose cheridire/ né sa né può chi dilàsù/ discende; perchéappressando sé al suo disire,/ nostrointelletto si profonda tanto,/ chedietrola memoria non può ire (Par.I, 4-9)

[No alto céu, onde mais a luz se incende/ eu fui, e vi tais coisas, que dizer/Não sabe ou pode quem de lá descende; ...Porque apressurando-se ao querer/ Sumo, o intelecto se aprofunda tanto/ Que a Memória não segue o seu correr.] (CAMPOS, 1998, p. 85)

Há uma tensão entre o intelecto em Dante e o caminho místico, que a luz paradisíaca deixa transparecer. Quase uma cisão. O que leva a uma recuperação de Lúcifer, de sua origem etimológica: lucem ferre, o que traz luzou fogo. Por sua vez, a mitologia judaico-cristã atribui a Lúcifer uma atitude rebelde. Na tradição clássica indicava a estrela da manhã, ou seja, o planeta Vênus (também conhecido como Phosporus). Em hebraico Helel, em grego $\omega \sigma \varphi$ ópos. Lúcifer é o nome com que é indicado Satanás, pela 
interpretação rabínica e depois patrística e que remontaria a um período anterior ao da queda do Paraíso. Na Divina Comédia o encontro com Lúcifer é realizado no Canto XXXIV do Inferno, o mesmo que descreve a transferência do Inferno para o Purgatório. Lá Lúcifer é apresentado como um corpo monstruoso plantado no açude, que com suas três caras mastiga Judas, Brutus e Cássio. Segundo uma tradição popular, Lúcifer seria dono da sabedoria superior, que é negada ao homem comum. O que estabelece por seu tamanho e caráter monstruoso e, ao mesmo tempo, sua potencialidade positiva, uma singular analogia com a figura do Golem, da tradição hebraica.

\section{Notas}

1. Comparando aqui a tradução de Haroldo de Campos com aquela - notável - de Graça Moura, nota-se a audácia do poeta e tradutor brasileiro: ele traduz nelciel com No alto céu. Com isso a tradução acentua o movimento ascendente, que é importante para sublinhar a transformação.

2. (97) Tre specchi prenderai; e i due rimovi / da te d'un modo, e l'altro, più rimosso,/ tr'ambo li primi li occhi tuoi ritrovi. 100 Rivolto ad essi, fa che dopo il dosso / ti stea un lume che i tre specchi accenda / e torni a te da tutti ripercosso.(97) Toma de três espelhos; um retira/ mais distante; mais cerca, lado a lado,/ iguala os outros dois; entre eles mira. 100 Estando tudo assim configurado, / vê que uma luz por trás os três acenda/ e a ti tonre o reflexo triplicado (CAMPOS, 1998, p. 107).

3. (88) Tu stesso ti fai grosso/ col falso imaginar, sì che non vedi / ciò che vedresti se l'avessi scosso.

(88) No falso engrossa o imaginar, e nada/ permite que tu vejas, e não vês/ quando veria a vista liberada (CAMPOS, 1998, p. 93).

4. e infin che'1 mar fu sopra noi richiuso (Inf.. XXVI, 142), (ALIGHIERI, 1975, p. 533). 


\section{Referências}

ALIGHIERI, Dante. La Divina Commedia. Milão: Rizzoli, 1975. 3 vols. [a c. D. Mattalia]

. Lettera a Cangrande della Scala. Tradução Maria Adele Garavaglia. Disponível em: <http://www.classicitaliani.it/dante/cangran.htm $>$. Último acesso em 01/01/2012.

AUERBACH, Erich. Figura. In: . Studi su Dante. Milano: Feltrinelli, 1991. p. 176- 226.

BORGES, Jorge Luiz. "Kafka e seus precursores". In: BORGES. Outras inquisições. 1989 , p. $490-498$

CAMPOS, Haroldo de. Pedra e Luz na Poesia de Dante. Prefácio Andrea Lombardi. Rio de Janeiro: Imago, 1998.

. Galáxias. São Paulo: Editora 34, 1984.

CORTI, Maria. La felicità mentale, Percorsi dellinvenzione e altri saggi. In: . Scritti su Cavalcanti e Dante. Torino: Einaudi, 2003.

DEVOTO, Giacomo. Avviamento all'etimologia. [Roma]: Le Monnier, 1990.

GRAÇA MOURA, Vasco. A Divina Comédia de Dante Alighieri. 2. ed. Lisboa: Bertrand, 1996.

Recebido em: 12/02/2014

Aceito em: 23/05/2014 